http://revistaurbanismo.uchile.cl

\title{
El potencial de espacios públicos y patrimonios edificados en barrios y vecindades de la Comuna de Independencia
}

The potential of public spaces and buildings in neighborhoods of the Commune of Independence

\section{Isabel Pavez Reyes}

\section{Filiación}

Investigadora en el departamento de urbanismo de la Facultad de Arquitectura y Urbanismo de la Universidad de Chile.

\section{Resumen}

Se indaga en el espacio urbano intersticial de la Comuna de Independencia, Santiago de Chile, el potencial de desarrollo de los espacios públicos y semi-públicos, para colaborar a la definición de acciones para la conservación, reconstrucción, complemento, reinstauración o instauración de estos en el marco de un planeamiento y diseño de espacios públicos, y regularización de predios y edificios de su entorno más comprensivo y sin derroche de recursos en un área histórica pericentral metropolitana que desea atraer nueva población residente.

\section{Palabras Claves}

Espacios públicos, coordinación de patrimonio urbano y arquitectónico, trazados viales locales, pericentro histórico de Santiago de Chile, comuna de Independencia.

\begin{abstract}
in this article there is an exploration of what is the state of unused spaces in independencia (municipality in santiago chile) and what are the potentialities in the development of public and semi public spaces as a collaboration towards the conservation, reconstruction, complementing, restoration of such spaces as part of a plan to design public spaces, regularization of the sites and buildings, that is more sensitive and less expensive and its goal is to draw new residents to this historical area in the metropolitan peri center.
\end{abstract}

\section{Key words}

Public spaces, coordination of the urban and architectural heritage, local streets layout, historical peri center of Santiago Chile, municipality of Independencia.

\section{Sumario}

1.- La necesidad de una política de espacios públicos en Independencia

2.- Los objetivos de la investigación

3.- Algunos planteamientos previos

4.-Los planos base especiales para esta investigación

5.- ¿Nuevas centralidades para Independencia en el siglo XXI?

6.- Los criterios para la definición de polígonos y subpolígonos de interés

7.- El caso del Subpolígono 1.A.: Independencia - Profesor Zañartu - La Paz -Santa María

8.- El concepto de desarrollo espacial aplicado al Subpolígono 1.A.

9.- Palabras finales

Referencias 


\section{1.- La necesidad de una política de espacios públicos en Independencia}

La inexistencia de una política de espacios públicos en la Comuna de Independencia debiera ser superada en función del objetivo de repoblamiento -un rol prioritario "Residencial y de Servicios Comunales"- definido en el "Plan Estratégico de Independencia" ${ }^{1}$ desde comienzos de la década de los años 1990.

"Identidad y vocación para la comuna", "necesidad de integración territorial", "más espacios públicos", "oferta más adecuada de áreas verdes" ("áreas verdes notablemente insuficientes y poco significativas"), "seguridad para el espacio público", "una imagen atractiva para la comuna"; "mejor calidad del entorno y del medio ambiente", son expresiones frecuentes en el diagnóstico de situación de Independencia.

El estudio citado ha estimado, por otra parte, que para consolidar el carácter residencial de la comuna se debería llevar a cabo -en lo espacial-: un proceso de renovación urbana que aporte una imagen que supere la imagen de deterioro; una densificación moderada que aumente la población residente; -el reconocimiento y refuerzo de la identidad de los barrios; -la configuración de una oferta de espacios públicos más adecuada a las actividades y dinámica de la población esperada.

Frente a estas necesidades, nuestra investigación quiso contribuir a esclarecer la situación de los espacios públicos existentes en el actual territorio comunal localización, tipo, superficie, entorno- , indagando, además, el potencial en el espacio intersticial de la Comuna para generar oferta nueva, diversa, y complementaria, en la perspectiva del incremento deseado de población residente. No se puede soslayar, por otra parte, los cambios en la composición de la población chilena previstos para el próximo futuro, donde destaca la duplicación del porcentaje de la población de adultos mayores $^{2[2]}$. Adicionalmente, se quiso contribuir a señalar algunas fuentes posibles de identidad espacial del habitante con su vecindad, barrio y comuna de residencia.

El territorio de la Comuna ha variado a través de las décadas -formado con parte de otras Comunas sea: totalmente (pertenencia a la Comuna de Santiago de 1934, y por varias décadas, (Fig. 1), o con diversos polígonos de su territorio actual (parte de Santiago con límite administrativo diferente al actual, de Conchalí y de Renca).

\footnotetext{
1 I. MUNICIPALIDAD DE INDEPENDENCIA, Plan Estratégico de Independencia, Fase I -Identificación de Temas Críticos, 1991, 31 págs.

2 PAVEZ R., M. Isabel (I. Responsable); SAHADY V., Antonio (Co-investigador alterno); DUARTE O., Patricio, y DURAN A., Martín (Co-investigadores. El potencial de espacios públicos y semipúblicos del pericentro histórico de Santiago: identificación de polígonos privilegiados en la Comuna de independencia y recomendaciones directrices de intervención. CONCURSO F.A.U. DE PROYECTOS DE INVESTIGACION ARQUITECTURA Y URBANISMO, GEOGRAFIA Y DISEÑO 1999, Departamento de Urbanismo - Departamento de Historia y Teoría de la Arquitectura, F.A.U. Universidad de Chile, 3 Volúmenes.

Revista de Urbanismo Nº11 - Diciembre de 2004
} 


\section{REVISTA DE}

http://revistaurbanismo.uchile.cl

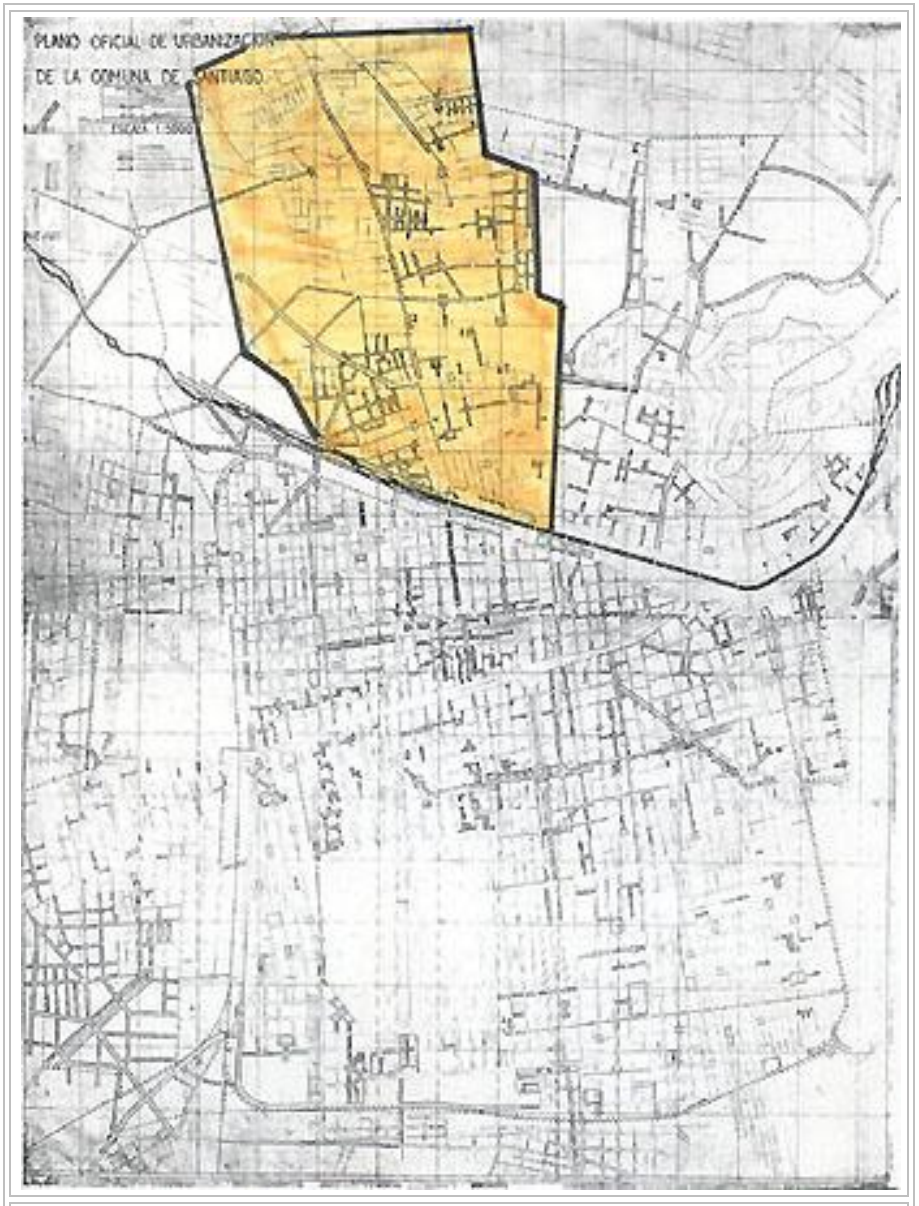

Fig.1. Territorio de la actual Comuna de Independencia (en amarillo) en "Plano Oficial de Urbanización de la Comuna de Santiago", 1939 (Karl Brunner 1934/39, copia matriz en Archivo del Departamento de Urbanismo F.A.U. Universidad de Chile).

Por tanto, si bien la Comuna cuenta con un conjunto de espacios públicos practicables, no cuenta con un "sistema" de espacios públicos -cuantitativa y cualitativamente adecuado- para ofrecer tanto a la población actualmente residente, como a la que vendría a vivir a la Comuna en el primer cuarto del siglo XXI.

Por otra parte, ha habido intervenciones no críticas de mejoramiento urbano puntual sobre espacios existentes (accesos, plazas, vías, etc.) que, además, no capturan oportunidades de integración de elementos de identidad, no completan proyectos, no logran armonía formal, ni economía de medios, ni diversidad de la oferta, ni utilizan el potencial de suelo, de trazado y otros.

También se constata pérdida -indiscriminada- de stock construido y espacio intersticial en el espacio privado, para ser reemplazado por propuestas puntuales que no participan de una política general de ocupación del espacio donde se establezcan Revista de Urbanismo Nº11 - Diciembre de 2004 


\section{REVISTA DE}

http://revistaurbanismo.uchile.cl

adecuadas relaciones entre espacio público, semi público y privado, y se realce el valor de los componentes de interés histórico-cultural arquitectónico y urbano existentes, en beneficio público y privado.

Cabe destacar que los estudios básicos realizados para un nuevo Plan Regulador ${ }^{3}$, en 1994, confirmaron, que la ubicación pericéntrica de la Comuna y sus ventajas comparativas, estaban provocando una creciente cantidad de solicitudes para localizar empresas y micro empresas de industrias, bodegas y talleres, lo cual ha provocado incrementos del valor del suelo, ha presionado la localización tendiendo a expulsar la vivienda directa e indirectamente, lo cual hacía preciso aclarar las áreas potenciales de localización industrial. Nuevas regulaciones están siendo requeridas también para precisar polígonos que debieran estar sujetos a programas de conservación, renovación y remodelación.

Pensamos que un Plan Regulador debería manifestar también una postura clara frente a diversos proyectos de interés metropolitano que ya impactan, o estarían impactando a futuro a la Comuna, como es el caso del sistema Ruta 5 Norte y acceso a Santiago. Nos parece también conveniente, una discusión sobre la propuesta de una Línea de Metro por Vivaceta -existente en el proyecto original del Metro de Santiago-, la nueva Costanera Norte y el eventual traslado de La Vega Central, que estaría liberado un polígono importante para otros usos ${ }^{4}$.

3 CONVENIO I. MUNICIPALIDAD DE INDEPENDENCIA - Facultad de Arquitectura y Urbanismo de la Universidad de Chile, Plan Regulador Comunal de Independencia. Informe de la $1^{a}$ Etapa, abril de 1994, 9 págs.

4 I. MUNICIPALIDAD DE INDEPENDENCIA, 1991, op. cit., p.12.

Revista de Urbanismo N${ }^{\circ} 11$ - Diciembre de 2004 


\section{REVISTA DE \\ ISSN 0717-5051}

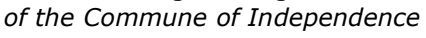

http://revistaurbanismo.uchile.cl

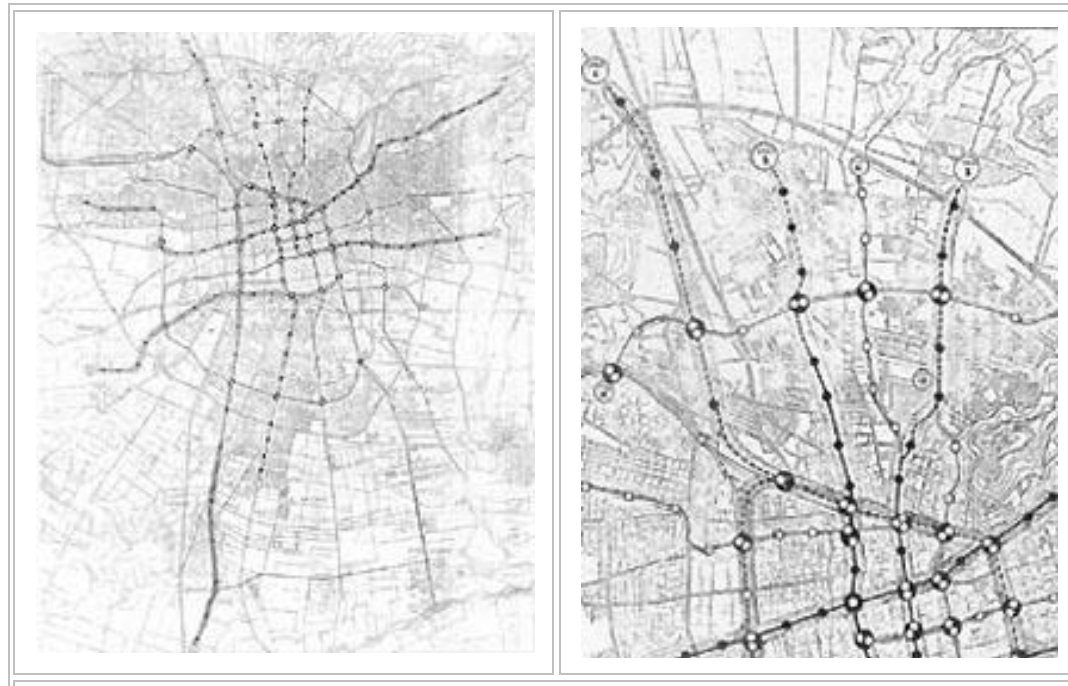

Fig. 2-A y 2-B. Trazado del Proyecto de Metro de Santiago, 1969, 15 Líneas (proyecto original), Dirección General de Metro, (Fdo.

J.Parrochia B., Director General), y detalle del bloque metropolitano norte.

Se observa en la Comuna de Independencia, el paso de la Línea 2 por Vivaceta, con su término en la Circunvalación Américo Vespucio.

También el paso de la Línea 11, variante, por El Guanaco, desde Avda. La Paz).

\section{2.- Los objetivos de la investigación}

Nuestro objetivo general ${ }^{5}$ fue indagar en el espacio urbano intersticial de Independencia el potencial de desarrollo de los espacios públicos y semi-públicos, para colaborar a la definición de acciones para la conservación, reconstrucción, complemento, reinstauración o instauración de estos- en el marco de un planeamiento y diseño de espacios públicos, y regularización de predios y edificios de su entorno- más comprensivo y sin derroche de recursos en este área histórica pericentral metropolitana.

Nuestros objetivos específicos fueron: -capturar nuevos elementos conceptuales y formales lógicamente posibles en el área de estudio que demuestren un potencial para el incremento de la oferta, la identidad, conectividad y diversidad de los espacios públicos. -Identificar polígonos con riqueza de elementos a integrar, para un particular tratamiento y normativa futura de forma y contenido, como áreas paradigmáticas para la difusión del desarrollo espacial. -Establecer directrices generales de planeamiento y

\footnotetext{
${ }^{5}$ PAVEZ R., M. Isabel, et al, op.cit.

Revista de Urbanismo N 11 - Diciembre de 2004
} 


\section{REVISTA DE URBANISMO \\ ISSN $0717-5051$}

\section{http://revistaurbanismo.uchile.cl}

diseño de espacios públicos, y regularización de predios y edificios del entorno en los polígonos identificados, como base de proyectos seccionales futuros.

Un análisis histórico diacrónico, tanto de las actividades sociales ${ }^{6}$ y hechos destacados ${ }^{7}$, como de las proposiciones en planificación urbana ${ }^{8}$ (proyectos formales de las escalas metropolitana y comunal -período 1934-1999-, incidiendo en la actual Comuna de Independencia), y también de la arquitectura patrimonial clasificada ${ }^{9}$, permitió una mejor comprensión del proceso de generación y cambio de los espacios públicos estructurantes de Independencia. Las totalidades, sub-totalidades y fragmentos de los objetos conceptuales y/o formales que existen mostraron la razón de coherencia que les dio sentido al origen ${ }^{10}$, mostrando, además, algunas posibilidades latentes para su eventual incorporación a proyectos de futuro ${ }^{11}$.

Por otra parte, una indagación sistemática en el espacio intersticial real (público y privado) permitió capturar nuevos elementos conceptuales y /o formales posibles de integrar en una red de espacios públicos y sus proyectos concretos de diseño urbano para el siglo XXI, que también incorporen los edificios patrimoniales existentes y donde se coordinen los nuevos elementos posibles con las totalidades, subtotalidades y fragmentos de espacios públicos heredados.

Finalmente, se identificó polígonos privilegiados de desarrollo, y se elaboraron recomendaciones para cada uno de ellos en lo referido a: regulación de predios y edificios del entorno de los espacios públicos y semipúblicos; edificios patrimoniales, y diseño de los espacios públicos.

Por último se estudiaron alternativas de trazados en los polígonos reconocidos, para efectos de promover una discusión tendiente a esclarecer el proyecto más adecuado en cada polígono o subpolígono.

\footnotetext{
6 Véase al respecto:

-PAVEZ, M.I., et al, op. cit., Tomo III "Culturas y razón de identidad histórica de la Comuna de Independencia: potencial de desarrollo en el espacio público", pp. 5-86. - Artículo de DURÁN, M., op. cit. en la Bibliografía adjunta.

7 Véase al respecto:

-PAVEZ, M.I., et al, op. cit., Tomo III "Culturas y razón de identidad histórica de la Comuna de Independencia: potencial de desarrollo en el espacio público", pp. 87-115. -Artículo de DUARTE, P., op. cit. en la Bibliografía adjunta.

8 PAVEZ R., M. Isabel, et. als., op.cit. Tomo I "El potencial de espacios públicos de nivel estructurante en la Comuna de Independencia", 81 págs.

9 ANDUAGA, Magda, DUARTE, Patricio, SAHADY, Antonio, Patrimonio arquitectónico de la Comuna de Independencia, Instituto de Restauración Arquitectónica, F.A.U. de la U. de Chile, 1996, 219 págs. ilustradas.

${ }_{10}$ El resultado de este análisis fue expuesto en el artículo: PAVEZ, M.I., "El Plan Brunner para Santiago: potencial de desarrollo de las totalidades, subtotalidades y fragmentos viales en la Comuna de Independencia 2000", en Revista de Urbanismo $\mathrm{N}^{\circ} 3$, publicación digital del departamento de Urbanismo de la F.A.U. de la U. de Chile, [En línea] http://revistaurbanismo.uchile.cl/n3/pavez2/i1/i1.html

11 PAVEZ R., M. Isabel, et al, op. cit. Tomo II "El potencial de espacios públicos y patrimonio edificado en barrios y vecindades de la Comuna de Independencia", 111 pág., y anexos.

Revista de Urbanismo No11 - Diciembre de 2004
} 


\section{REVISTA DE URBANISMO \\ ISSN 0717-5051}

http://revistaurbanismo.uchile.cl

\section{3.- Algunos planteamientos previos}

Para nuestro estudio participamos de las siguientes ideas:

-Los estudios y proposiciones en arquitectura y en urbanismo deben estar al servicio de la habitabilidad y la urbanidad de las ciudades asumiendo la riqueza de manifestaciones de la sociedad, e incrementando por ello la diversidad, asociada hoy al concepto de bien común (NASELLI, 1994).

-El patrimonio urbano y arquitectónico debe constituir un sistema con sus partes efectivamente interrelacionadas, donde la red de espacios públicos asume un valor estructurante básico, con la participación de la arquitectura de valor destacado y los espacios semi-públicos (NASELLI, 1994).

-Los instrumentos de análisis de nuestras ciudades -que requieren ir forjándose en un permanente diálogo con la realidad-, deben tener como principal referencia el carácter de discontinuidad y ruptura, característico de nuestra realidad chilena y latinoamericana (WAISMAN, 1983).

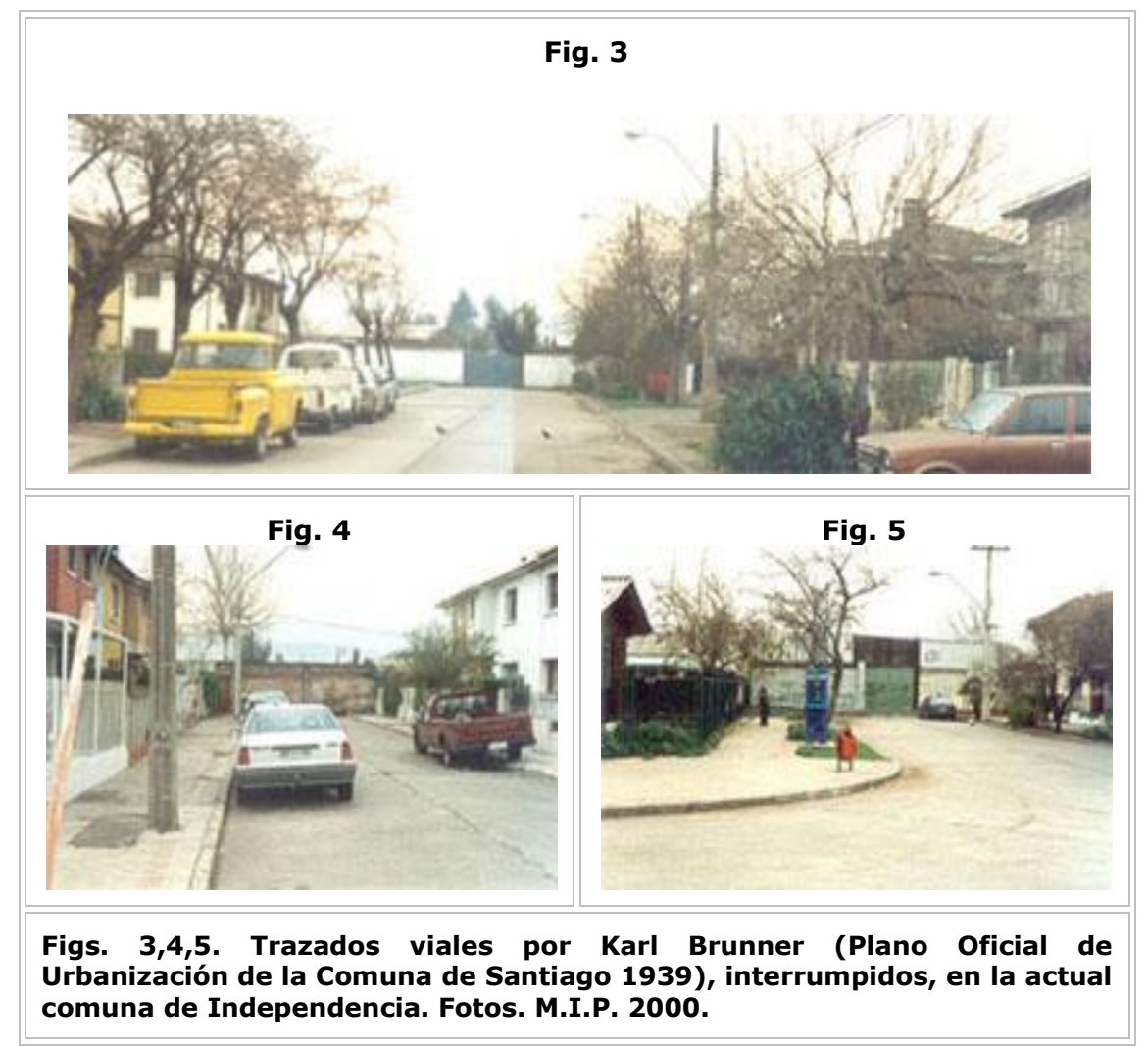




\section{REVISTADE URANO

http://revistaurbanismo.uchile.cl

Por otra parte, se participa y promueve una evolución conceptual para:

LA FORMA URBANA: desde un concepto originado sólo en predeterminaciones de tipologías y arquetipos: La forma urbana es buena porque tiene una calidad de diseño conforme a la cultura urbana-arquitectónica consagrada, hasta un concepto dinámico, derivado de la interacción de los diversos planos de la realidad: Los espacios urbanos y arquitectónicos son buenos porque posibilitan y facilitan la riqueza de las manifestaciones socio-culturales (NASELLI, 1994). Los elementos del repertorio de formas consagradas serán aportes a dichos objetivos, toda vez que demuestren pertinencia al caso.

EL PATRIMONIO EXISTENTE: desde un concepto entendido como obras puntuales y sólo de arquitecturas valiosas existentes en la ciudad, hasta una noción de amplitud urbana: El valor puntual de los objetos patrimoniales urbanos y arquitectónicos, aumenta en razón del incremento de las relaciones entre ellos y con la totalidad urbana-cultural en que están insertos. Participan los espacios existentes y potenciales públicos, semipúblicos y privados, construidos o intersticiales, en todas sus escalas.

LOS PLANES Y PROYECTOS HEREDADOS: desde una lectura únicamente a partir de lo que se hace presente físicamente hoy como totalidades, sub-totalidades y/o fragmentos en la realidad actual, hasta una lectura atenta de las formas heredadas en su contexto de origen: El conocimiento del proceso de superposición de planes y proyectos de planificación urbana -muchas veces truncados, detenidos o desvirtuados permitirá interpretar y rescatar de manera informada, el valor real de las señales que ellos emiten hoy para su eventual participación en nuevos proyectos con valor urbano estructurante. 


\section{REVISTA DE URBANISMO
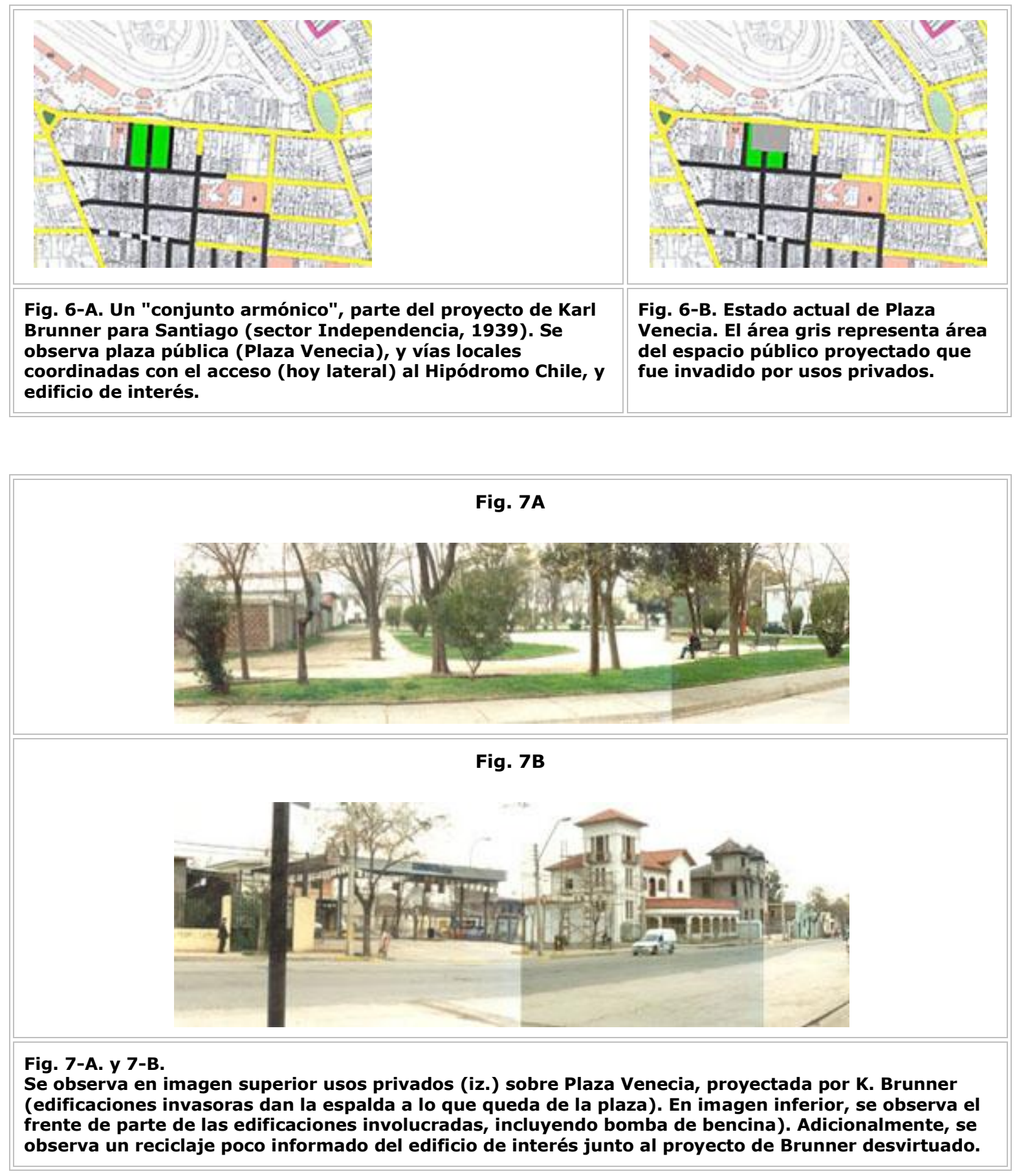


\section{REVISTA DE URBANISMO \\ ISSN 0717-5051}

http://revistaurbanismo.uchile.cl

\section{4.- Los planos base especiales para esta investigación}

Se realizaron dos planos-base especiales para los ejercicios de lectura y análisis propuestos, a saber:

4.1.- Sobre plano base de la Comuna de Independencia 1998 (Escala 1:5000), se destacó:

-los trazados viales y de áreas verdes anteriores al Plan Brunner 1934/39;

- los trazados de vías y plazas verdes propuestos por K. Brunner (realizados y no realizados) para el "sector Independencia" en Plano Oficial de Urbanización de la Comuna de Santiago 1939; -los trazados viales posteriores y complementarios al Plan Brunner, y los edificios patrimoniales de la Comuna de Independencia 1996.

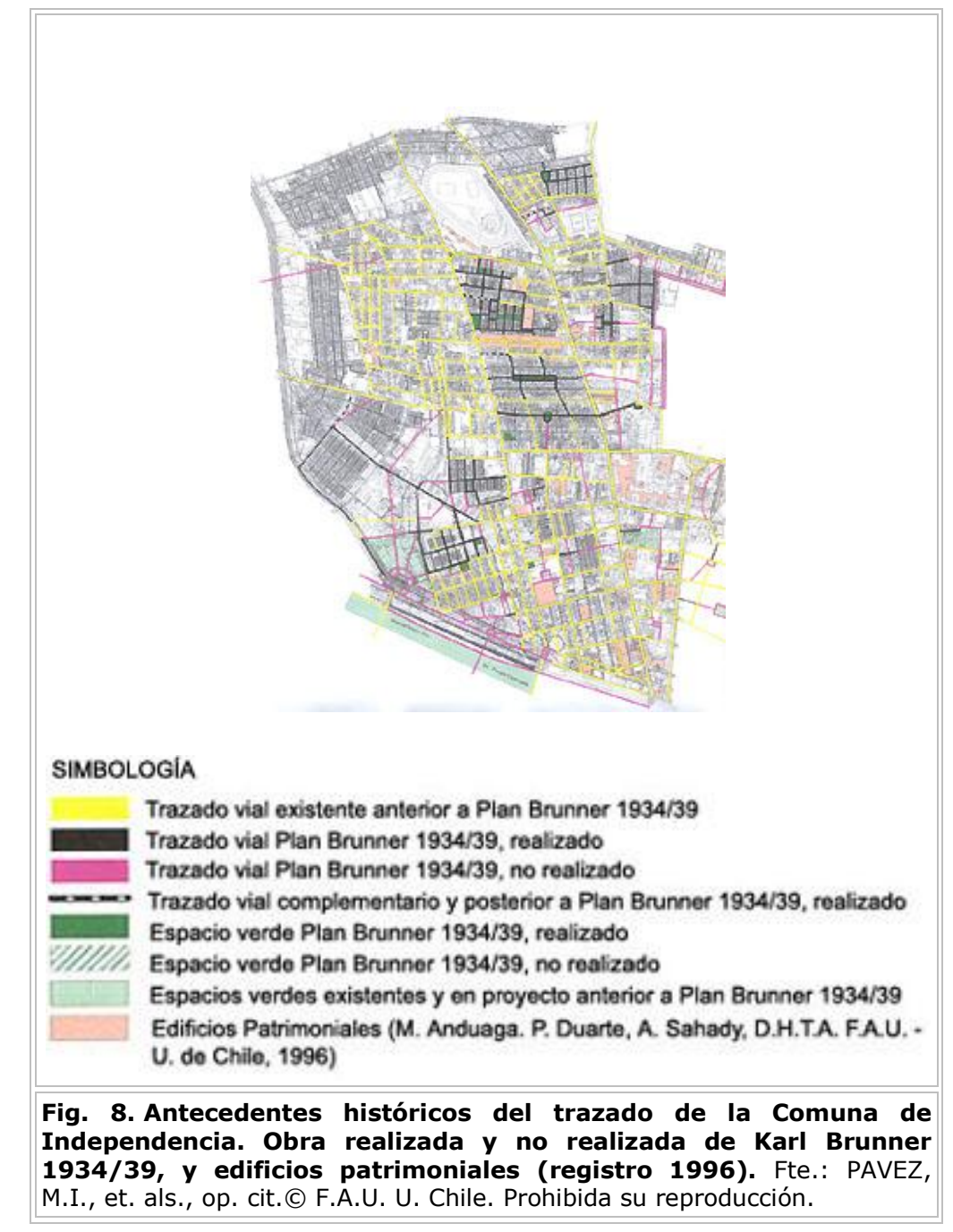




\section{REVISTA DE \\ ISSN 0717-5051}

http://revistaurbanismo.uchile.cl

4.2.- Sobre plano base de la Comuna de Independencia 1998 (Escala 1:2500), se destacó la siguiente información ${ }^{12}$ :

-Espacios verdes públicos con fines esencialmente paisajísticos y ecológicos, clasificados en tres subgrupos (adjunta información de superficie);

-Espacios verdes públicos funcionales a la actividad recreacional no programada de niños (más de 7 años) y adultos, clasificados en tres subgrupos (adjunta información de superficie);

-Espacios verdes públicos funcionales a la actividad recreacional no programada de infantes (adjunta información de superficie);

-Espacios públicos y semipúblicos verdes residuales (Escuela "Movimiento Moderno") (adjunta información de superficie);

-Edificios patrimoniales clasificados;

-Trazados viales y de áreas verdes propuestos por K. Brunner, realizados.

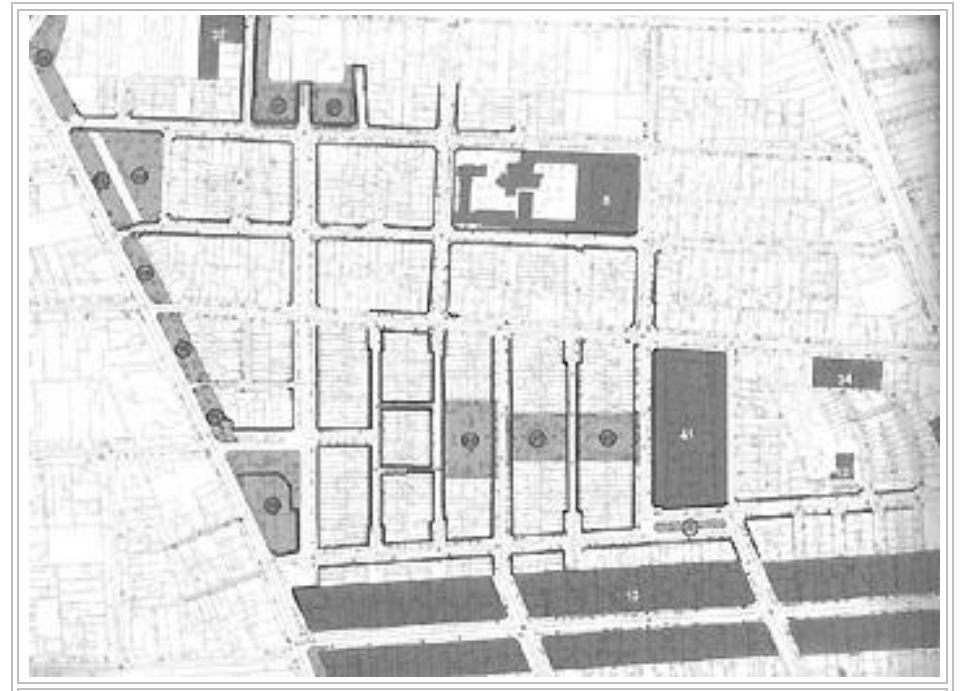

Fig.9. Segmento de plano de la Comuna de Independencia, con trazados realizados de K. Brunner (remarcados), edificios patrimoniales clasificados y la totalidad de espacios verdes actuales clasificados, sobre plano catastro 1998.

@ F F.A.U. U. Chile. Prohibida su reproducción.

Cabe destacar que la voluntad del urbanista austríaco Karl Brunner para lograr conexidad y conectividad en la ciudad en lo referido a sus trazados de escala intercomunal y comunal, cobra especial fuerza cuando se observa el escalón de barrios y vecindades, que abren -con especial consideración de los desplazamientos peatonales- amplias alternativas de recorridos tanto oriente-poniente (abiertos al paisaje de las cordilleras de Los Andes y de La Costa), como norte-sur y

12 Véase al respecto el artículo: M.I.PAVEZ R. "Espacios verdes en la comuna de independencia: tribulaciones a partir de un listado municipal y reflexiones varias", en BOLETÍN INVI N041 Santiago, ISSN 0716-5668, Ed. INVI, F.A.U. - U. Chile, nov. 2000, pp.71-80.

Revista de Urbanismo N¹1 - Diciembre de 2004 


\section{REVISTA DE URBANISMO \\ ISSN 0717-5051}

http://revistaurbanismo.uchile.cl

combinaciones, punteados por espacios verdes de las mismas escalas de barrio y vecindad.

Se observa en el "sector Independencia" del Plan Brunner, que estos últimos se han mantenido en buen estado de conservación por cincuenta o más años, aunque podemos imaginar que esta situación podría comenzar a cambiar en breve, y a una velocidad creciente, habida cuenta de los efectos espaciales derivados de la densificación residencial prevista para la Comuna de Independencia y del proceso de individualización del automóvil, entre otros.
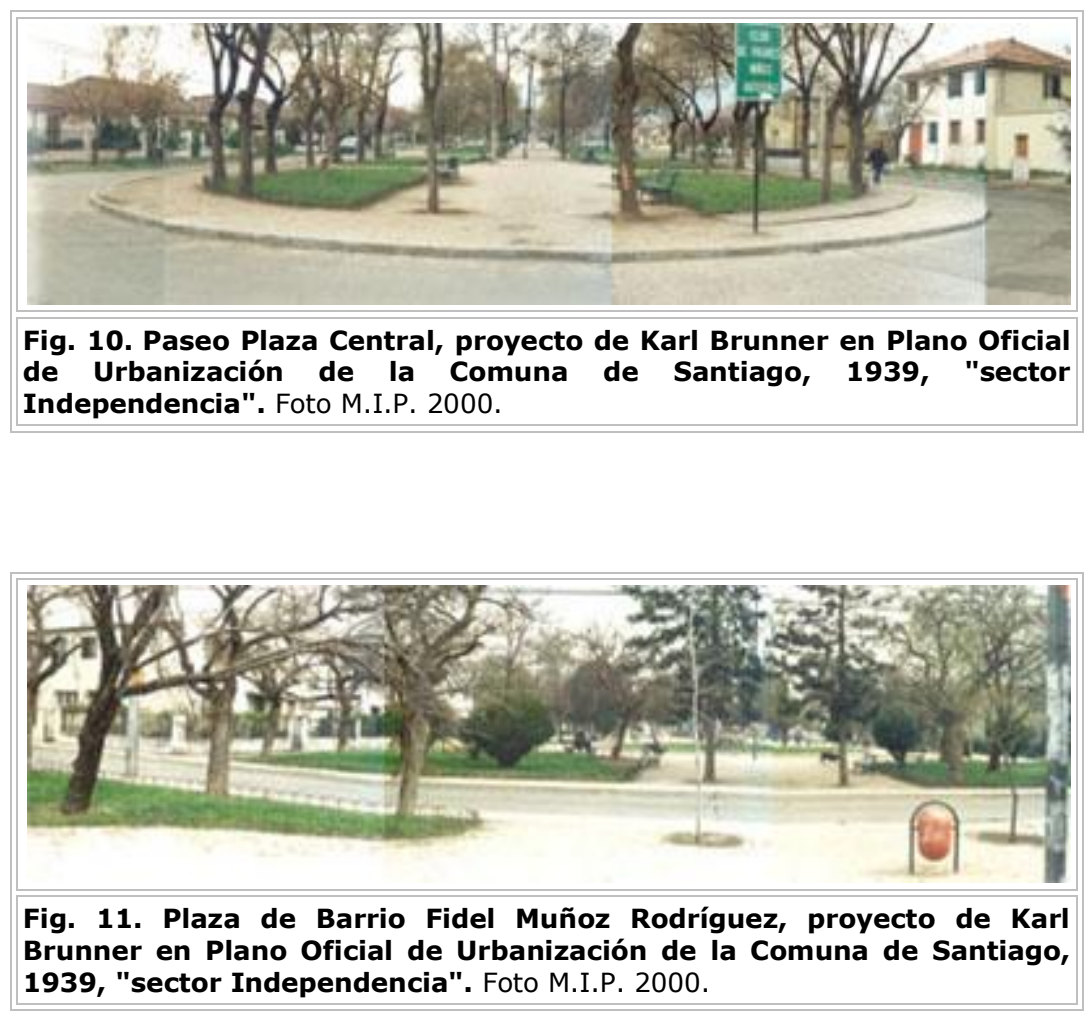

Observamos en el "sector Independencia" de la comuna de Santiago de 1934, que ningún recurso de trazado de espacio público preexistente fue ignorado o derrochado por el urbanista austríaco, quien conforme a los principios de la ciudad occidental, hizo su construcción esencialmente desde el espacio público, en la perspectiva del logro de "una obra de arte mayor equilibrada"13.

13 Vid. CORTÉS, Fernando, "La Construcción de la ciudad como espacio público", en revista DE ARQUITECTURA N8, Especial Karl Brunner, Santiago de Chile, F.A.U. U. Chile, pp.14-19.

Revista de Urbanismo Nº11 - Diciembre de 2004 


\section{REVISTADE URANO \\ ISSN 0717-5051}

http://revistaurbanismo.uchile.cl

Adicionalmente, la "Ordenanza Local de Edificación para la Comuna de Santiago", aprobada por el Arqto. Roberto Humeres, y publicada en el Diario Oficial, $N^{\circ} 18.486$, de 19 de octubre de $1939^{14}$, señaló en su Artículo 14:

"Cuando a consecuencia de la edificación alta y por consiguiente de mayor capacidad, se estimare que las condiciones de tránsito y estacionamiento en las calles o sector correspondiente hubiesen sido perjudicadas, la Dirección de Obras Municipales podrá exigir a los propietarios la apertura de calles o plazoletas interiores para estacionamientos de vehículos a nivel o el aprovechamiento de los subterráneos con el mismo fin.

La superficie que podrá exigir la Municipalidad para destinar a estacionamiento, sea a nivel o en subterráneo, será hasta de $36 \mathrm{~m} 2$ por cada cinco departamentos, oficinas o locales comerciales destinados a ser arrendados separadamente o por cada $300 \mathrm{~m} 2$ de superficie de piso edificado. En los casos en que se proyecten aperturas de calles o plazoletas interiores, estas deberán ser trazadas de acuerdo con directivas generales que fijará la Dirección de Obras Municipales para la división de las manzanas, en tal forma, que los diversos trozos de calles o plazoletas abiertas en una misma manzana, formen en lo posible un sistema único de vialidad"15.

Observamos la conciencia del impacto de una eventual mayor densidad edificada y de población, y su repercusión en los espacios privados, semiprivados y públicos requeridos, como asimismo la voluntad de generar grupos y subgrupos locales unitarios e integrados a la vialidad general.

La voluntad de Brunner para configurar o completar vecindades, para luego coordinar trazados en beneficio de la conexidad y conectividad entre ellas constituyendo barrios definidos al interior de los ejes viales comunales fundamentales, otorga una impronta hasta el día actual a Independencia, cuya importancia de presente y de futuro no debiera ignorarse.

\footnotetext{
14 Aprobada el 4 de agosto de 1939, y modificada por los decretos supremos números 1.145 y 3.375 , de 20 de marzo, 26 de julio de 1940 y Ac. M. 298, de 24 de septiembre de 1940. "Ordenanza Local de Edificación para la Comuna de Santiago", publicada originalmente en el Diario Oficial, $\mathrm{N}^{\circ} 18.486$, de 19 de octubre de 1939, reproducida en: BOLETIN DEL COLEGIO DE ARQUITECTOS N¹4, de octubre de 1948, Santiago de Chile, pp.3-36.

15 BOLETIN DEL COLEGIO DE ARQUITECTOS N²14, cit., p.10

Revista de Urbanismo N 11 - Diciembre de 2004
} 


\section{REVISTA DE URBANISMO

http://revistaurbanismo.uchile.cl

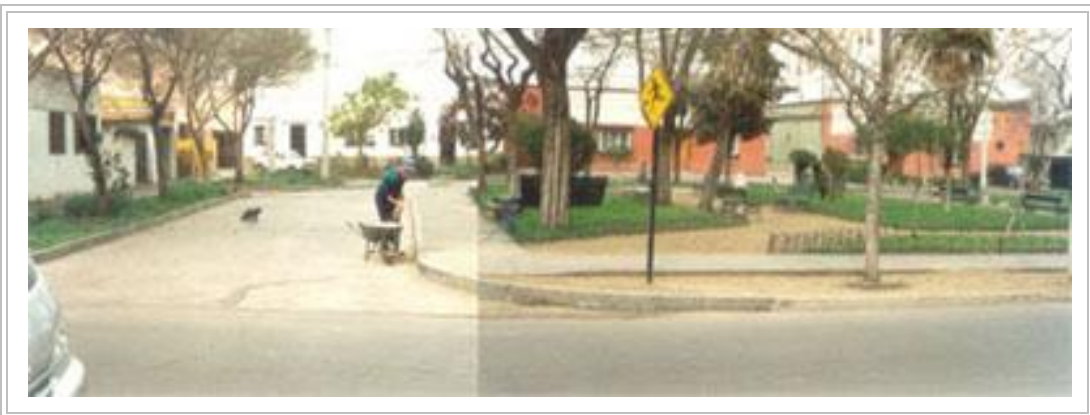

Fig. 12-A. Plaza Cádiz, parte de un subsistema proyectado por Karl Brunner, conforme se aprecia en sección de plano (Plano Oficial de la Comuna de Santiago, 1939, K. Brunner), ajunto (Vid. Infra., a la iz.)

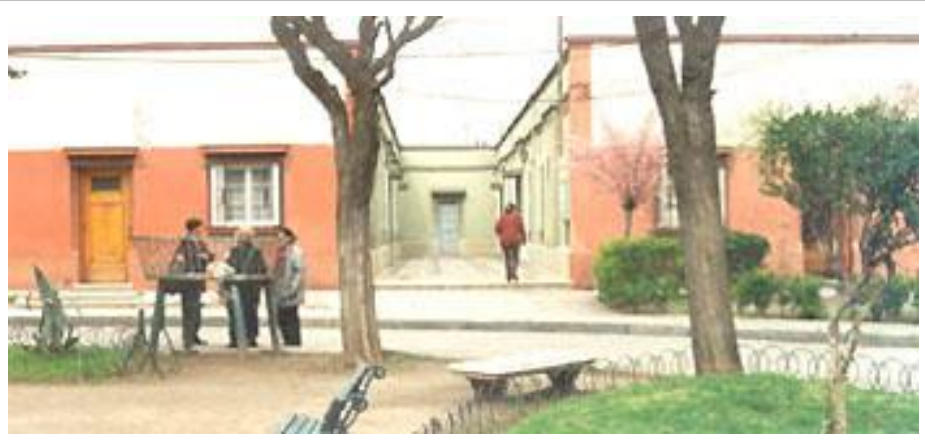

Fig. 12-B. El pasaje Cádiz no corresponde a un "pasaje típico" de la Comuna de Independencia, sino al resultado de la desvirtuación de una proposición en el proyecto de Brunner.

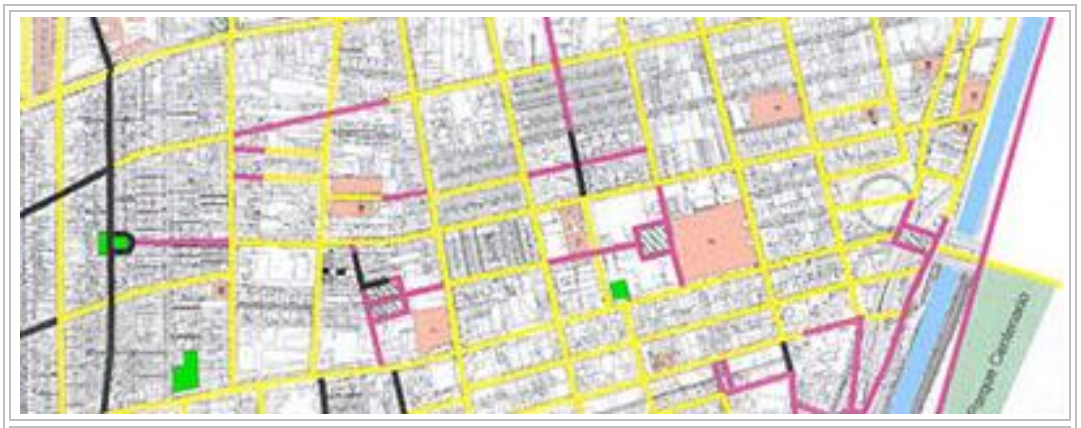

Fig. 12-C. (Norte a la iz.) Se observa que Brunner dispone la plaza Cádiz como forma de acometida de la prolongación al norte de calle Escanilla, uniendo de esta forma la costanera norte del río Mapocho (Santa María) con Domingo Sta. María, vía, esta última que atraviesa
el
bloque
metropolitano
norte.

(c) F.A.U. U. Chile. Prohibida su reproducción. 


\section{REVISTA DE \\ ISSN 0717-5051}

http://revistaurbanismo.uchile.cl

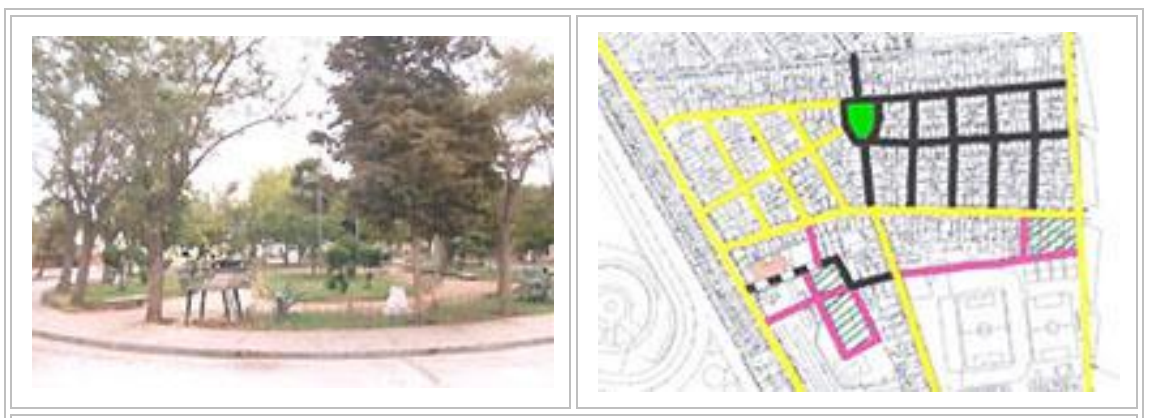

Fig. 13-A y 13-B. Plaza F. Vivaceta, un proyecto de K. Brunner realizado en el "sector Independencia" 1934/39, comprendiendo también trazados viales (color negro) para completar una vecindad existente en 1934 (color amarillo), según plano adjunto. Foto: M.I.P. 2000.

Aun en el marco del proceso creciente de individualización del automóvil antes mencionado, la realidad de la población de menor movilidad (los ancianos, cuya representación en la composición de la población chilena se duplicará muy pronto; los niños; los adolescentes, y los minusválidos, todos los cuales no pueden conducir vehículos), impone una cuidadosa consideración del peatón en los nuevos trazados viales, y en los espacios recreacionales y de sociabilización públicos y semipúblicos que pudieran surgir en la comuna de Independencia.

Si la falta de acción pública de la época en que se aplicó el Plan Brunner- que no se podía justificar por la carencia de fondos en el Municipio para afrontar debidamente el pago de las expropiaciones y el financiamiento de las nuevas obras de urbanizaciónimpidió la realización de parte de las proposiciones del plano de Brunner, cabe preguntarse cuánto ha evolucionado hasta ahora la capacidad de gestión pública para efectos de una real utilidad de las recomendaciones de trazado y entorno de los espacios públicos que la presente investigación sugiere en vistas de la densificación residencial que la comuna desea para sí misma.

En la perspectiva del ordenamiento espacial para el desarrollo urbano del siglo que comienza, la aproximación al concepto de utilidad pública no debería definirse tanto por la patrimonialidad pública y la obra pública, como por la vocación operacional de la expropiación con efectos de reorganización y redistribución conforme a una política urbana.

Por otra parte, el tipo de gobierno urbano asociado a una "cultura del conflicto", debiera evolucionar hacia la "cultura de la negociación", evitando la confusión entre democracia y gestión.

El urbanismo que porta la presente investigación quiere ser práctico "fuera de proyecto", sin soslayar la vida política local y sin obligar a la comunidad a amarrarse a una imaginería técnica. Por el contrario, se inscribe en una voluntad de repolitización de la vida urbana, presentándose como una oferta a la política urbana, como ayuda a la conceptualización del problema de los espacios públicos. 


\section{REVISTA DE URBANISMO \\ ISSN 0717-5051}

http://revistaurbanismo.uchile.cl

No se trata de un urbanismo "sin proyecto" sino de una forma de exigencia en cuanto a la manera de hacer el proyecto, dándose el espacio y el tiempo para componerlo. Los debates no serán, así, "sobre un proyecto", sino "para un proyecto". Un debate que sirva para descubrir o configurar el proyecto mismo.

En estos debates es importante tener siempre presente que los espacios públicos - la vialidad, sola o ligada a otros espacios públicos, como resuelve la presente aproximación- tienen diversos roles, más allá de la circulación, creando la animación y el carácter de la ciudad.

La vialidad y los espacios intersticiales públicos, son lugares de comunicación social con una función sicológica importante; lugar de actividad e intercambio, elementos de la composición urbana, espacio de implantación de redes diversas, soporte de la circulación y de los transportes.

Diversos profesionales, arquitectos, sociólogos, paisajistas, geógrafos, entre otros pueden y deben colaborar el nivel local para que los espacios públicos donde los habitantes desarrollan la civilidad, sean adecuados a sus actividades y ambiente.

\section{5.- ¿Nuevas centralidades para Independencia en el siglo XXI?}

Si se divide la comuna de Independencia en cuatro polígonos equivalentes en superficie aproximadamente, la Avda. Vivaceta y Domingo Santa María representan los ejes "cardo" y "decumanus" de esta partición básica.

Nuestra selección de polígonos mayores desestimó, para efectos de este estudio, el polígono sur-poniente, que corresponde a la "Población Presidente Ríos", según sus límites originales: Domingo Santa María, Vivaceta, Santa María, y Ruta 5 Norte (construida en varias etapas entre 1945 y 1959).

Dada la importancia histórica de esta población que representó - muy tempranamente en Chile ${ }^{16[}$ - el modelo moderno asociado a la forma de la periferia urbana para la ciudad de Santiago, hemos considerado que el caso de los espacios públicos actuales en esa gran superficie es de una complejidad que amerita especial atención, la cual no fue posible dentro de los plazos y objetivos de esta investigación ${ }^{17}$.

16 La Carta de Atenas de redactó en 1933, tuvo su primera edición, clandestina en plena ocupación, en 1942, y se difundió en Chile desde 1946.

17 Véase, entre otros, sobre la Población Presidente Ríos:

CAJA DE LA HABITACIÓN POPULAR, Departamento Técnico, "Población Presidente Ríos", en Boletín del Colegio de Arquitectos $N^{\circ} 7$, agosto de 1945, y

LOPEZ M., Waldo, Evaluación de Centros Pilotos de Equipamiento Comunitario en Chile, en MINVU, Dirección de Planificación de equipamiento Comunitario, Documento de Trabajo N7, abril de 1969, 64 págs., pp.2425.

Revista de Urbanismo N¹1 - Diciembre de 2004 


\section{REVISTA DE URBANISMO \\ ISSN 0717-5051}

http://revistaurbanismo.uchile.cl

Se observará además que la importancia funcional e histórica de la Avda. Independencia hasta el momento de la construcción de la Carretera Panamericana, vino a significar hasta hoy una impronta espacial y funcional fuerte que fue dando un mayor peso de imagen a los polígonos nor-oriente y sur-oriente, teniendo como centralidad la propia Avda. Independencia que vio una concentración de actividades y servicios de importancia no sólo comunal sino también intercomunal.

No obstante, la configuración de la Carretera Panamericana - Ruta 5 Norte, con la proposición de una variante por Vivaceta al Complejo Vial Norte-Sur para acceso a la ciudad de Santiago, y la proposición de una Línea de Metro en el Sistema de Metro MOP desde los años 1960, en Vivaceta, vienen a sugerir la posibilidad de un reequilibrio territorial hacia el poniente de Vivaceta, que potencie los dos cuartos occidentales de la Comuna.

Sin duda, el territorio comunal de Independencia, que hoy es percibido como un conjunto de pedazos de territorios liberados por otras comunas, requiere una suerte de refundación al comenzar el siglo XXI, que debe ser sustentada por debates informados respecto del verdadero potencial espacial que ella presenta, por su condición de comuna de status metropolitano, y dentro de ello, por su condición de comuna del pericentro histórico de la metrópolis principal de Chile.

Podría retomarse la hipótesis sobre Vivaceta, en su próximo futuro, como una vía llamada a constituir una nueva centralidad de la Comuna de Independencia en el siglo XXI, constituyendo, conforme a su propia escala, un sistema par con Independencia, repotenciando con ello un conjunto de vías trasversales diversificadas en un "sistema escalera".

El sistema Vivaceta contiene en su longitud, cuatro puntos de interés a la imagen e identidad urbana, ubicados dos al sur de Avda. Santa María, los edificios clasificados $\mathrm{N}^{\circ} 2$ (Monumento Nacional $\mathrm{N}^{\circ} 85$,) ex Iglesia y Monasterio Provincial del Buen Pastor, y No7 (Parroquia Santo Tomás de Aquino).

Al norte de la Avda. Domingo Santa María, se ubican el conjunto residencial clasificado N¹3 (Población Los Castaños), y el conjunto Nº60 (Hipódromo Chile).

En lo referido a la Avda. Independencia (Camino Real - Cañadilla - Avda. "de la Independencia"), su reconsideración formal y funcional en la perspectiva del siglo XXI, pasaría por la realización de toda la extensión de la vía estructurante intercomunal El Guanaco-Bélgica, proyectada por la planificación urbana metropolitana oficial (en 1939, confirmada en 1960 y en 1994). Esta vía fue prevista como alternativa a Independencia, para su desahogo, a partir de la acometida desde el centro de la ciudad, por Avda. La Paz (posibilidad hoy bloqueada por un nuevo diseño de la plaza de acceso al Cementerio General). No puede soslayarse por otra parte, el antecedente del proyecto del Sistema de Metro original, que contempló una Línea en el eje de El Guanaco-Bélgica (eje de simetría del bloque metropolitano norte). 


\section{6.- Los criterios para la definición de polígonos y subpolígonos de interés}

Teniendo presentes las reflexiones referidas hemos considerado, un conjunto de criterios que estimamos deberían concurrir para la definición de polígonos con suelo urbano y características tales que hicieran posible y recomendable una reforma interior. Ellos debían presentar:

- un potencial para generar o contribuir a generar circuitos integradores del patrimonio arquitectónico clasificado y del trazado urbano público y semipúblico destacado;

- la posibilidad de desarrollar espacio público de carácter estructurante básico en los espacios intersticiales al centro de las manzanas, y nuevos conjuntos residenciales en torno a dicho espacio, los que deberían contemplar un adecuado diseño de entorno de aquellos;

- la posibilidad de acoger trazados viales que incrementen la conectividad entre barrios y vecindades tanto en sentido norte-sur, como oriente-poniente, y también algunos espacios de estancia, desplegando al menos un porcentaje de espacio del escalón de jerarquía intermedia en ambos casos, toda vez que sea posible;

- la posibilidad de incrementar una cierta diversidad de espacios públicos en función de la mayor población residencial que la comuna desea atraer;

- la posibilidad de desarrollar el beneficio público y privado en virtud de la coordinación de la acción de iniciativa privada con las acciones de enmarcamiento básico estudiadas por el sector público;

- la posibilidad de contribuir al incremento de la identidad espacial comunal, de barrios y vecindades, con raíz propia y conforme a conceptos formales y funcionales vigentes;

- la posibilidad de establecer nuevas relaciones funcionales y formales en la línea de frontera con las comunas de Recoleta y Santiago en prioridad;

- la posibilidad de permitir la ubicación y organización de un centro cívico comunal, a la escala de una comuna metropolitana en el área del pericentro histórico más destacado en las imágenes colectivas de los habitantes de toda la ciudad.

Estos polígonos y subpolígonos derivados fueron estudiados simultáneamente tanto en su potencial interior como en sus posibilidades de coordinación entre ellos.

En lo referido a la necesidad de integrar los patrimonios edificados para una potenciación mutua entre estos y los espacios públicos, cabe destacar que la Comuna de Independencia coincide con uno de los sectores más antiguos de la ciudad. Precisamente la calle Independencia concentra en su primer tramo un buen número de edificios que tienen casi un siglo de vida. Es necesario reconocer que no han sido debidamente valorizados $\mathrm{y}$, consecuentemente, respetados. Pese a que una parte de 


\section{UEVISTADE \\ ISSN 0717-5051}

http://revistaurbanismo.uchile.cl

ese patrimonio ya se ha perdido irremisiblemente, se postula la necesidad de proteger lo que aún permanece en pie, en el marco de su entorno, delimitando con claridad la zona de protección correspondiente.

De esta forma se definieron 4 polígonos, conteniendo en total, 9 subpolígonos ${ }^{18}$.

Se estableció un conjunto de recomendaciones válidas para todos los subpolígonos polígonos, en lo referido a:

- regulación de predios y edificios del entorno de los espacios públicos y semipúblicos (26 recomendaciones);

- sobre el patrimonio edificado reconocido (14 recomendaciones);

- sobre diseño de los espacios públicos (14 recomendaciones).

Se estudiaron alternativas de trazado de vías y espacios verdes en cada subpolígono, y recomendaciones específicas para discusión en la perspectiva de un proyecto. A continuación se presenta el juego de alternativas de trazado para uno de los subpolígonos.

18 POLIGONO 1. SUR-ORIENTE: VIVACETA - DOMINGO SANTA MARÍA -SAN JOSÉ -PROFESOR ZAÑARTU LA PAZ - SANTA MARÍA

Subpolígono 1.A. Independencia - Profesor Zañartu - La Paz - Santa María

Subpolígono 1.B. Vivaceta - Rivera - Independencia - Santa María

Subpolígono 1.C. Vivaceta - Gamero - Independencia - Rivera

Subpolígono 1.D. Vivaceta - Domingo Santa María - San José - Profesor Zañartu - Independencia - Gamero. POLÍGONO 2. SUR-PONIENTE: RUTA 5 NORTE- DOMINGO SANTA MARÍA -VIVACETA

POLÍGONO 3. NOR-PONIENTE: RUTA 5 NORTE - CATORCE DE LA FAMA - VIVACETA - DOMINGO SANTA MARÍA

Subpolígono 3.A. Ruta 5 Norte - Bravo de Saravia - Las Cañas - Nueva de Matte - Vivaceta- Domingo Santa María

Subpolígono 3.B. Ruta 5 Norte -Catorce de la Fama - Vivaceta - Nueva de Matte - Las Cañas - Bravo de Saravia

POLÍGONO 4. NOR-ORIENTE: Avda. Vivaceta - Cañete - Pérez Cotapos - El Guanaco - Avda. México -Lindero Poniente del Cementerio General - Avda. Domingo Santa María

Subpolígono 4.A. Avda. Independencia - Santa Laura - Avda. México - Lindero poniente del Cementerio General - Avda. Domingo Santa María

Subpolígono 4.B. Vivaceta - Hipódromo Chile - Independencia - Domingo Santa María

Subpolígono 4.C. Avda. Vivaceta - Cañete - Pérez Cotapos - Avda. El Guanaco - Santa Laura Hipódromo

Chile.

Revista de Urbanismo N¹1 - Diciembre de 2004 
http://revistaurbanismo.uchile.cl

\section{7.- El caso del Subpolígono 1.A.: Independencia - Profesor Zañartu - La Paz - Santa María}

Destacados de contenido del POLÍGONO 1 SUR-ORIENTE, al cual pertenece.

- 45 edificios patrimoniales clasificados -un 70,3\% del total en Independenciasiendo 18 de ellos de origen residencial y 27 institucionales, conteniendo el principal hito edificado perceptible desde la Ruta 5 Norte en su acceso a la ciudad de Santiago, desde la costanera sur, y diversos otros lugares.

- Potencial para generar y, en especial, completar circuitos, integradores del patrimonio arquitectónico y urbano, público, semipúblico y privado.

- Potencial para desarrollar espacio público de carácter estructurante básico en los espacios intersticiales al centro de algunas manzanas, y nuevos conjuntos residenciales en su entorno.

- Posibilidades de incrementar la conectividad entre vecindades en los subpolígonos, tanto en sentido norte- sur, como oriente-poniente, desplegando el escalón de jerarquía intermedio para viales (15-20 m) y espacios de estancia (1-1,5 hás), en un contexto formal de relativa regularidad del trazado público y privado para facilitar la ordenación urbanística.

- Posibilidad de contribuir al incremento de la identidad espacial comunal, de barrios y vecindades, con raíz propia, fuertemente inspirados en las proposiciones precedentes del Plan Brunner, conforme a conceptos formales y funcionales vigentes.

- La posibilidad de establecer nuevas relaciones funcionales y formales en la línea de frontera con la comuna de Recoleta y la comuna de Santiago, en lo referido a Avda. La Paz (1.550 m de longitud); y sistema Avda. Santa María - Costanera Norte ( $800 \mathrm{~m}$ de longitud). Ambos casos ameritan un futuro estudio seccional que considere las nuevas estructuras internas de los subpolígonos relacionados, tanto de la comuna de Independencia como de la comuna de Recoleta.

- La posibilidad de instaurar ciertos tipos de espacios públicos y de estancia, y adecuar otros ya existentes, en función de la mayor densidad residencial que la comuna desea atraer. En especial, un potencial de primera prioridad para desarrollar un centro cívico a la escala de comuna metropolitana, junto a edificio Monumento Nacional existente. 


\section{REVISTA DE URBANISMO \\ ISSN 0717-5051}

http://revistaurbanismo.uchile.cl

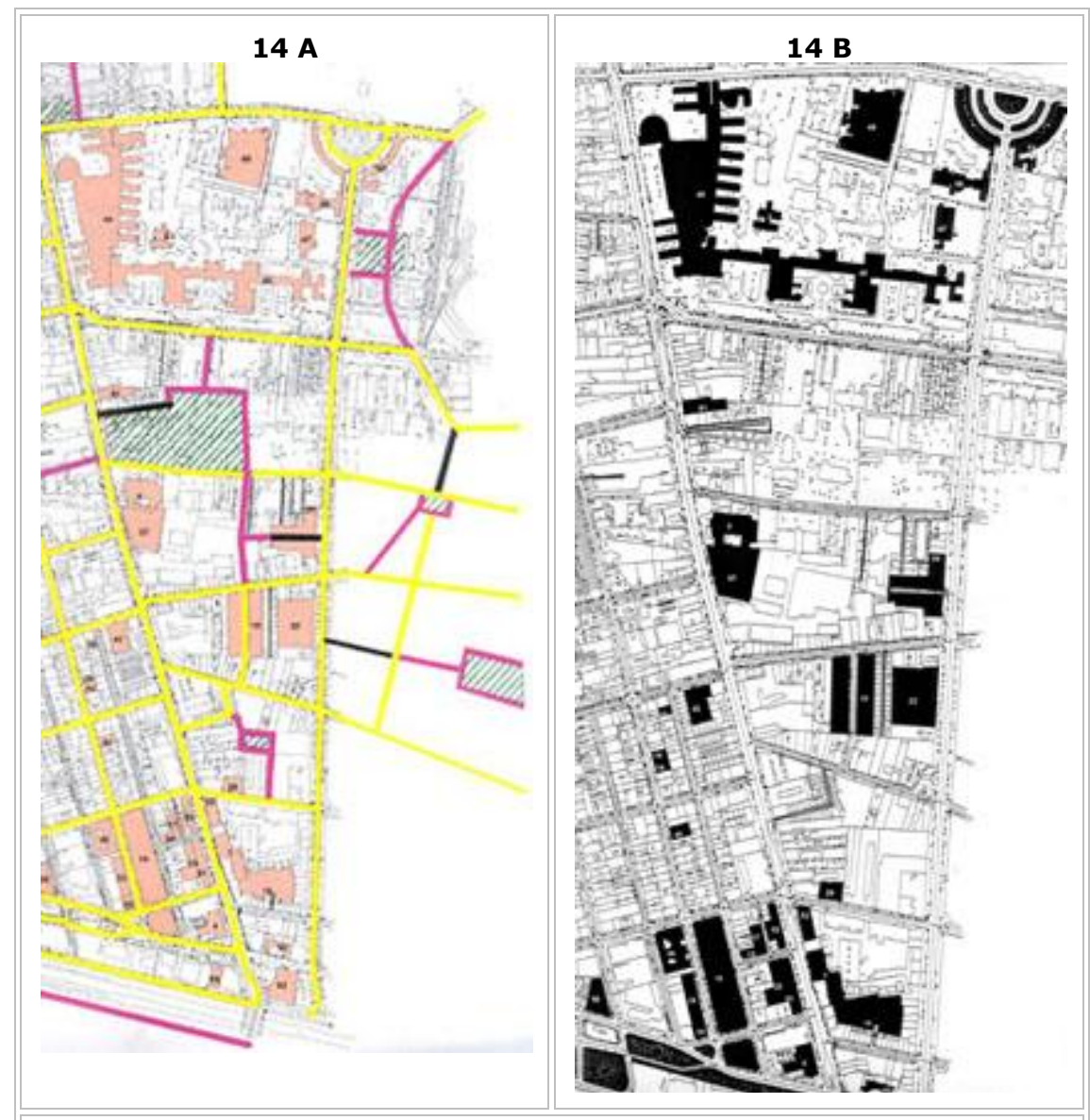

Fig. 14-A. Trazados de Karl Brunner en el subpolígono Independencia Prof. Zañartu - La Paz - Santa María, y edificios patrimoniales.

Detalle de proposición de K. Brunner en el Plano Oficial de la Comuna de Santiago de 1939.

(Vid. Supra. Simbología correspondiente, en Fig.1).

F.A.U. U. Chile. Prohibida su reproducción.

Fig. 14-B. Situación actual del subpolígono Independencia - Prof. Zañartu - La Paz - Santa María, al año 2000, y edificios patrimoniales.

\section{8.- El concepto de desarrollo espacial aplicado al Subpolígono 1.A.}

Dado que el Subpolígono $1 \mathrm{~A}$, contiene 7 atraviesos en sentido oriente-poniente al interior de los límites del subpolígono, y ninguno en sentido norte-sur, sería deseable generar una centralidad interna -atravesando y uniendo a la vez un conjunto de vecindades-, entre Independencia y Avda. La Paz, que se desarrolle entre el edificio 


\section{REVISTA DE URBANISMO \\ ISSN 0717-5051}

http://revistaurbanismo.uchile.cl

clasificado $\mathrm{N}^{\circ} 45$ Hospital Clínico José Joaquín Aguirre, en calle Profesor Zañartu, y el edificio clasificado $\mathrm{N}^{\circ} 16$, ofreciendo una secuencia urbana a través de una vía central norte-sur de aproximadamente 900 metros de largo, jalonada de espacios libres de estancia diversos al servicio de nuevas áreas residenciales en su entorno y sistemas viales complementarios anexos.

Dentro de los siete atraviesos oriente-poniente del subpolígono, -de los cuales dos tienen un rol de enlace de comunas, -Gamero/Santos Dumont, y Gral. Borgoño/Artesanos-, es posible desarrollar un potencial de atravieso en Pinto/Dávila Baeza, mediante apertura de tramo menor (al oriente de Independencia), que permitiría ligar todo el borde sur de la población Presidente Ríos (vía de servicio de la Ruta 5 Norte, en Polígono 2, sur-poniente), con la Avda. Recoleta a través de Dávila Baeza. Este eje se presenta como posibilidad, aproximadamente a 600 metros al norte de Santa María.

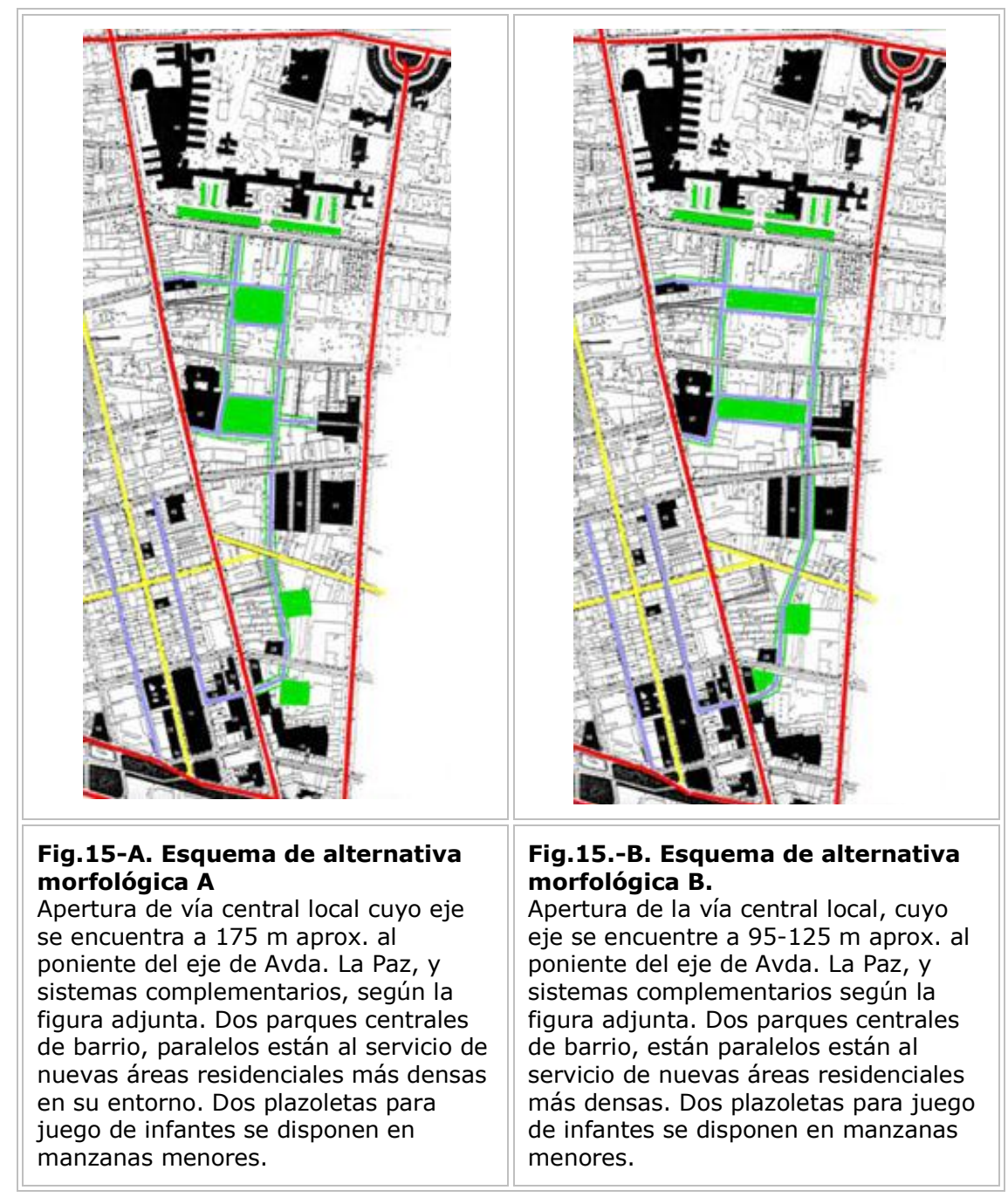




\section{REVISTA DE of the Commune of Independence

http://revistaurbanismo.uchile.cl

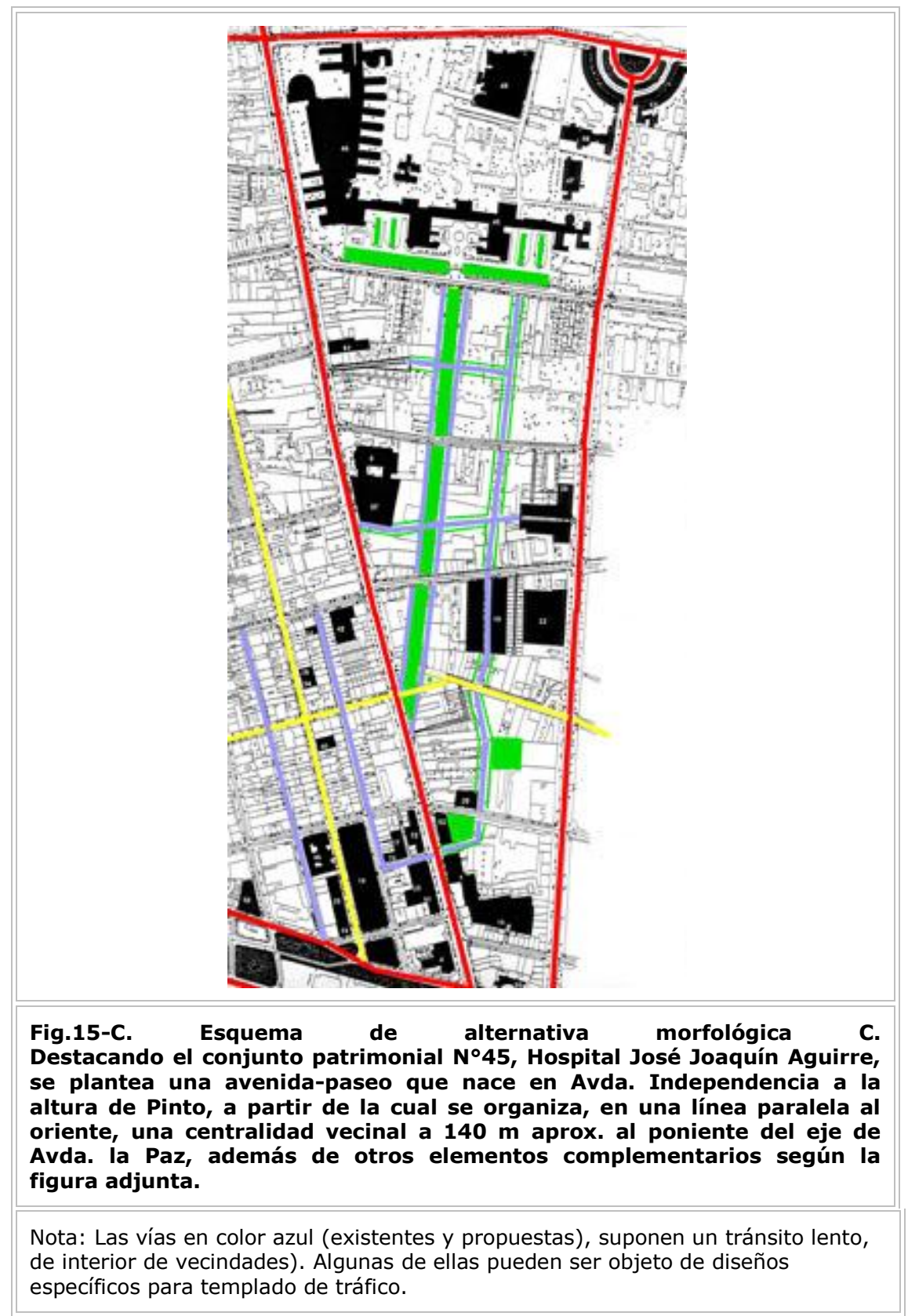




\section{REVISTA DE URBANISMO \\ ISSN 0717-5051}

http://revistaurbanismo.uchile.cl

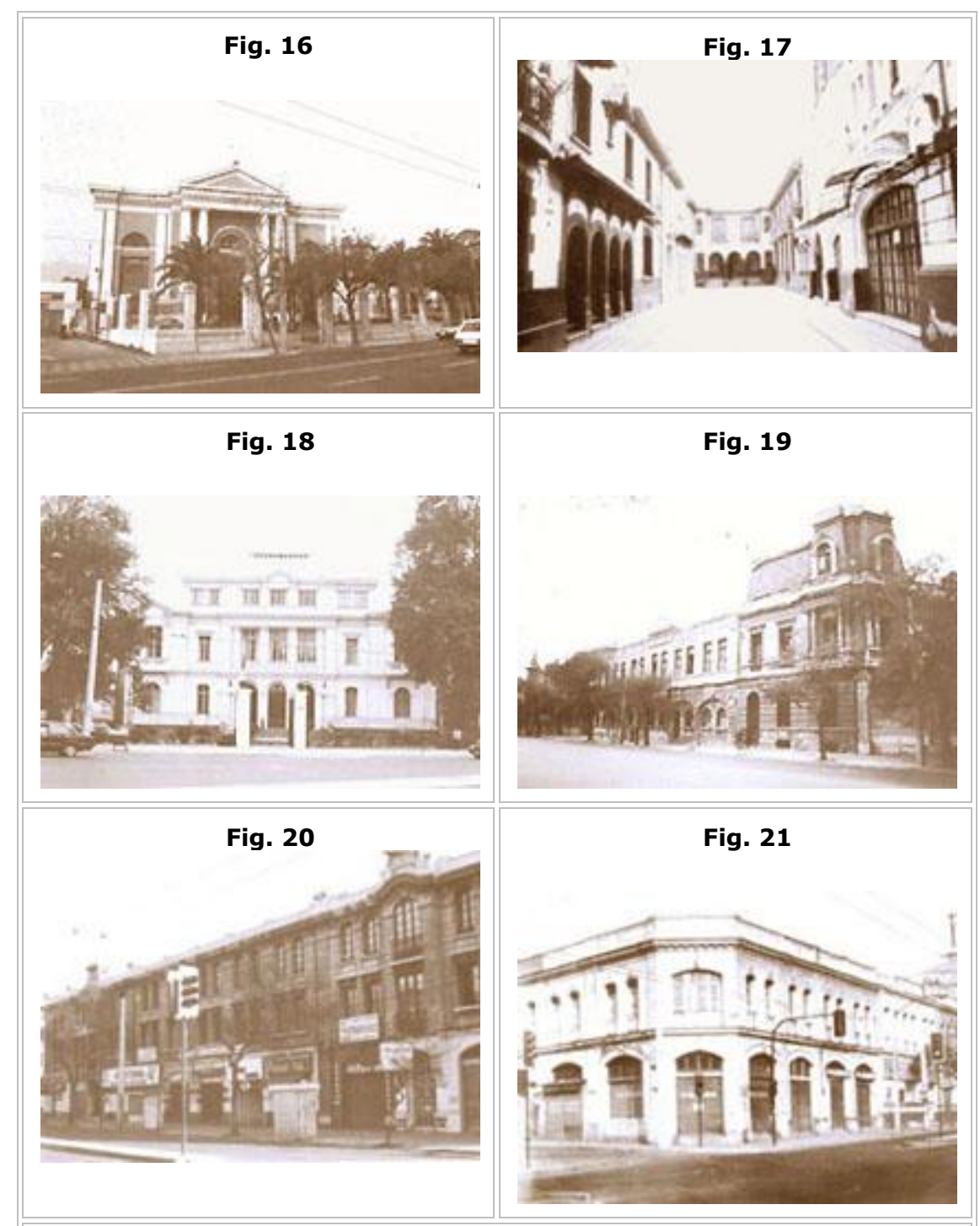

Figs. 16,17,18,19,20,21. Algunos de los edificios patrimoniales en el subpolígono presentado: Parroquia de la Estampa Volada de N. Sra. del Carmen; conjunto residencial Capitol; edificio ex Instituto de Higiene; ex fábrica de Cerveza Andrés Ebner; edificio de renta; edificio de renta. Fte.: Fotografías en: -ANDUAGA, Magda, DUARTE, Patricio, SAHADY, Antonio, Patrimonio arquitectónico de la Comuna de Independencia, Instituto de Restauración Arquitectónica, F.A.U. de la U. de Chile, 1996, 219 págs. ilustradas. 


\section{REVISTADE \\ ISSN 0717-5051}

http://revistaurbanismo.uchile.cl

\section{9.-Palabras finales}

1. Se ha identificado polígonos con diversos grados de riqueza de elementos existentes o potenciales a integrar, donde es posible un particular tratamiento y normativa futura de forma y contenido, como áreas paradigmáticas para la difusión del desarrollo espacial integral.

2. Se ha capturado nuevos elementos conceptuales y formales lógicamente posibles en el área de estudio que demuestran la existencia de un grado potencial medio para el incremento de la oferta, la identidad, conectividad y diversidad de los espacios públicos de barrios y vecindades en la comuna de Independencia. En materia de vialidad es posible desarrollar el escalón intermedio de vías conectoras de barrios y vecindades, generando con ello centralidades que se estiman necesarias a la evolución positiva del área urbana comunal. En lo referido a espacios de estancia, es posible equilibrar la oferta de barrio de la comuna, mediante la creación de algunas unidades de Parque de Barrio en un tamaño mínimo (2 Hás), y un aumento de la cantidad de espacios verdes vecinales asociados a nuevos conjuntos residenciales y su vialidad estructurante interna. Esta última, a su vez, puede permitir circuitos integradores de patrimonio edificado clasificado, aumentando con ello el sentido de identidad de vecindades y barrios.

3. Se ha establecido directrices espaciales específicas para cada polígono identificado, en materia de Planeamiento Urbano de espacios públicos y semipúblicos, como base de proyectos seccionales futuros de desarrollo espacial urbano.

4. Se ha establecido recomendaciones válidas para todos los polígonos, en lo referido a: regulación de predios y edificios del entorno de los espacios públicos y semipúblicos, el patrimonio edificado reconocido, el diseño de los espacios públicos, más algunas recomendaciones específicas.

\section{Referencias}

-ANDUAGA, Magda, DUARTE, Patricio, SAHADY, Antonio, Patrimonio arquitectónico de la Comuna de Independencia, Instituto de Restauración Arquitectónica, F.A.U. de la U. de Chile, 1996, 219 págs. ilustradas.

-CHILE - I. MUNICIPALIDAD DE INDEPENDENCIA, Plan Estratégico de Independencia, Fase I -Identificación de Temas Críticos, 1991, 31 págs.

-CONVENIO I. MUNICIPALIDAD DE INDEPENDENCIA - FACULTAD DE ARQUITECTURA Y URBANISMO DE LA UNIVERSIDAD DE CHILE, Plan Regulador 
http://revistaurbanismo.uchile.cl

Comunal de Independencia. Informe de la $1^{a}$ Etapa, abril de 1994, 9 págs.

-DUARTE, Patricio, "Razón de identidad histórica y posibilidades de expresión en el espacio público de Independencia", en REVISTA DE URBANISMO $\mathrm{N}^{\circ} 4$, publicación digital del Departamento de Urbanismo de la F.A.U. de la Universidad de Chile, julio 2001.

[En línea]

http://revistaurbanismo.uchile.cl/n4/duarte/html

-DURAN A., Martín, "Actividades en el espacio público de la Comuna de Independencia: captura de culturas para estudios base de reformulación de espacios públicos formales", en REVISTA DE URBANISMO $N^{\circ} 7$, publicación digital del Departamento de Urbanismo de la F.A.U. de la Universidad de Chile, enero 2003.

[En

http://revistaurbanismo.uchile.cl/CDA/urb_portada/0,1328,ISID\%253D257,00.html

-HOFER, Andreas, Karl Brunner y el Urbanismo Europeo en América Latina, Bogotá, Colombia, El Áncora Editores, Corporación La Candelaria, 2003, 235 págs. ilustradas $\mathrm{b} / \mathrm{n}$.

-LEBLANC-BAZOU, E.; CORONIO, G., y J.P. YOLY, Environnement et équipements urbains, CRU, 1971.

-NASELLI, César, "Arquitectura, Ciudad, Cultura y Sociedad", en Revista Notas del Sur, N03, Córdoba, Argentina, Ed. F.A.U., U. Nacional de Córdoba, Abril de 1994, pp.30-34.

-PAVEZ R., M. Isabel (I. Responsable); SAHADY V., Antonio (Co-I. alterno); DUARTE O., Patricio, y DURAN A., Martín (Co-investigadores). El potencial de espacios públicos y semipúblicos del pericentro histórico de Santiago: identificación de polígonos privilegiados en la Comuna de independencia y recomendaciones directrices de intervención. Concurso F.A.U. Proyectos de Investigacion Arquitectura, Urbanismo, Geografia y Diseño 1999, D. de Urbanismo - D. de Historia y Teoría de la Arquitectura, F.A.U. Universidad de Chile, 3 volúmenes:

Volumen I "'I potencial de espacios públicos de nivel estructurante en la Comuna de Independencia", 81 págs.

Volumen II "El potencial de espacios públicos y patrimonio edificado en barrios y vecindades de la Comuna de Independencia", 111 pág., y anexos. Volumen III "Culturas y razón de identidad histórica de la Comuna de Independencia: potencial de desarrollo en el espacio público", 115 págs.

Nota: Tanto avances preliminares como resultados de este estudio fueron expuestos en:

- XVI Congreso Nacional del Colegio de Arquitectos de Chile, Valparaíso, 27 al 30 de octubre de 1999. 


\section{REVISTA DE \\ URBANISMO \\ ISSN 0717-5051}

http://revistaurbanismo.uchile.cl

-Encuentro Intercambios de Bienes Culturales e Imaginarios Sociales, F.A.U. U. ChileMINEDUC, abril de 2001.

-PAVEZ, M. Isabel, "El Plan Brunner para Santiago: potencial de desarrollo de las totalidades, subtotalidades y fragmentos viales en la Comuna de Independencia 2000", en REVISTA DE URBANISMO N³, publicación digital del Departamento de Urbanismo de la F.A.U. de la Universidad de Chile, agosto 2000. [En línea] http://revistaurbanismo.uchile.cl/n3/pavez2/i1/i1.html

-REVISTA "DE ARQUITECTURA" N8, Especial "Karl Brunner - Austria, Chile, Colombia, Panamá". Santiago de Chile, F.A.U. U. Chile, 1996.

-WAISMAN, Marina, "Los instrumentos del pensamiento" en: CA N035. Catálogo IV Bienal, Agosto de 1983, pp. 130-131. 